\title{
Crenças associadas a serpentes no estado do Ceará, Nordeste do Brasil
}

Hugo Fernandes-Ferreira ${ }^{1,3 *}$, Rono Lima Cruz $^{2}$, Diva Maria Borges-Nojosa ${ }^{3} \&$ Rômulo Romeu Nóbrega Alves $^{4}$

${ }^{1}$ Laboratório de Mastozoologia, Universidade Federal da Paraíba, João Pessoa, Paraíba, Brasil.

${ }^{2}$ Departamento de Biologia e ${ }^{3}$ Núcleo Regional de Ofiologia. Universidade Federal do Ceará, Fortaleza, Ceará, Brasil.

${ }^{4}$ Departamento de Biologia, Universidade Estadual da Paraíba, Campina Grande, Paraíba, Brasil.

\begin{abstract}
Resumo - As serpentes, desde os primórdios da humanidade, são alocadas em relatos míticos e lendários de diversas etnias e regiões de todo o mundo devido à sua capacidade histórica de despertar o imaginário popular. No Brasil, em praticamente todas as regiões, existe uma grande riqueza de crenças envolvendo esses animais. A fim de realizar um levantamento etnográfico sobre as crenças e suas respectivas inferências científicas envolvendo ofídios no estado do Ceará, Nordeste do Brasil, foram realizadas, entre os anos de 2008 e 2010, entrevistas semiestruturadas com "especialistas locais" selecionados nos municípios de Aratuba, Pacoti e Mulungu (área serrana); Itapajé, Irauçuba e Tururu (área sertaneja) e o litoral de São Gonçalo do Amarante e Caucaia (área litorânea). Nas áreas abordadas, há uma diferenciação entre "cobras com ou sem veneno", sendo que a maioria das serpentes consideradas peçonhentas pelos entrevistados não possuem potencial venômico letal ao ser humano. Os entrevistados afirmam a prioridade de uso do soro antiofídico em caso de acidentes, porém eles consideram outros procedimentos caseiros como eficazes. Para determinadas espécies de serpentes, foram levantadas crenças constituídas por assimilações de caracteres morfológicos, fisiológicos e ecológicos, a maioria das quais não corrobora a literatura zoológica. Isso acontece provavelmente porque o sentimento de medo impede uma aproximação que pudesse promover um conhecimento popular que corroborasse de maneira mais consistente o conhecimento científico. A relação conflituosa entre humanos e serpentes leva a uma justificativa leiga para o abate indiscriminado desses animais, causando problemas ambientais e de saúde pública graves, que devem ser solucionados principalmente através de políticas públicas de educação ambiental, prevenção e tratamento de acidentes ofídicos.

Palavras-chave adicionais: conservação, etno-herpetologia, etnozoologia, folclore, herpetologia.
\end{abstract}

\begin{abstract}
Folklore concerning snakes in the Ceará State, northeastern Brazil) - Snakes, since the dawn of humanity, make part of an amount of legendary histories and mythes of the whole world because of their true capability in increasing the popular imaginary. In Brazil, in almost all areas, there is an abundant folklore about these animals. An ethnographic survey about the beliefs and the respective scientific considerations involving snakes in Ceará State, northeastern Brazil, were carried out between 2008 and 2010. Semi-structured interviews were carried out with selected 'local experts' in the municipalities of Aratuba, Pacoti and Mulungu (mountain region); Itapajé, Irauçuba and Tururu (semi-arid region) and São Gonçalo do Amarante and Caucaia (coastal area). In the study areas, there is a local differentiation between 'snakes with and without venom', although even the majority of snakes considered venomous by the locals are not lethal to humans. The interviewees indicated a preference in the use of snake anti-venum in case of snake bites, however, they also considered that home remedies were effective. For certain specific snakes, we described the folklore characterized by assimilation of morphological, physiological and ecological features, the majority of which are not corroborated by the zoological literature. This is probably because the sense of fear makes it difficult to promote folklore in a manner that is more consistent with scientific knowledge. The conflicting relationship between humans and snakes has led to a common law justification for the indiscriminate hunting of these animals causing serious environmental and health problems that can only be addressed through public policies directed towards environmental education, and the prevention and treatment of snakebites.
\end{abstract}

Additional key words: conservation, ethnoherpetology, ethnozoology, folklore, herpetology.

As serpentes, desde os primórdios da humanidade, são alocadas em lendas, mitos, fábulas e crenças dos mais variados grupos étnicos e religiosos em todo o mundo e, possivelmente, é o representante do Reino Animal mais relacionado a esses tipos de relatos (Morris \& Morris 1965; Oliver 1968; Greene 1997; Andreu 2000). Elas excitam a imaginação humana mais do que qualquer outro grupo animal

\footnotetext{
*Autor para correspondência: hugofernandesbio@gmail.com Editor responsável: Marcelo Alves Ramos

Recebido: 16 maio 2011; aceito: 5 set. 2011.
}

e são relacionadas com o mais variado leque de fatores, como medo, coragem, respeito, gratidão, poder, virilidade, criação, destruição, sorte, azar, cura, bondade, maldade, entre outros (Oliver 1968). No entanto, o sentimento de temor natural do ser humano ao se deparar com um ofídio é o mais representativo nessa relação. Wilson (1984) afirma que a ofidiofobia possa ser inclusive um produto da própria evolução humana. Esse temor pode ser expresso tanto por uma simples postura de defesa como por fobias psicopatológicas graves, comuns em todas as regiões do mundo (Smith \& Davidson 2007). 
Um dos relatos mais conhecidos em todo o globo, possivelmente o mais influente no Brasil e no Ocidente, é a passagem bíblica cristã, contida no livro de Gênesis, em que uma serpente ludibria Eva, a primeira mulher feita por Deus, para que ela comesse o fruto da árvore proibida, a que lhe possibilitaria o discernimento do bem e do mal. Apesar da existência de citações sobre serpentes em livros bíblicos como Êxodo e Mateus, relacionando-as com caracteres benévolos e principalmente malévolos, o capítulo três do livro de Gênesis pode ser um dos principais motivos de aversão humana aos ofídios no Ocidente, onde a religião cristã é mais difundida no mundo, pois desde então, as serpentes estariam condenadas por Deus e pelos seus seguidores à eterna penitência. Com o passar dos anos, desenvolveu-se uma forte correlação entre esses animais e a transgressão dos valores divinos, incluindo o paralelismo com a figura antagônica do Demônio (Morris \& Morris 1965; Frederico 2003).

Vizotto (2003) descreve, em um levantamento etnográfico sobre mitos, crenças e lendas sobre ofídios de diversas partes do mundo, dezenas de relatos provenientes das Mitologias Grega, Maia, Asteca, Incaica, Etrusca, Hindu, Egípcia, Nórdica, Japonesa, Mesopotâmica e das regiões norte, sul e meso-americanas, além de países como Austrália, Nova Guiné, Sumatra, China, Camboja e Borneo. Somadas a isso, 19 lendas típicas do Brasil completam a lista, a maioria da região amazônica. Além disso, o autor lista 22 principais crenças populares brasileiras envolvendo assimilações errôneas da população sobre a biologia desses animais. O ambiente sertanejo, segundo o autor, é o principal meio de disseminação dessas crenças. Diversas produções bibliográficas, científicas e literárias, abordam crenças encontradas no Brasil e no mundo, demonstrando o quanto esse grupo animal é capaz de interferir no imaginário popular, independente da região onde ele ocorra (Vanzolini 19561958; Oliver 1958; Morris \& Morris 1965; Nomura 1996; Andreu 2000; Marques 2001; Sandrin et al. 2005; Araújo 2004; Alves et al. 2006; Santos-Fita 2008).

O sentimento de aversão justificado pelo risco de letalidade de algumas serpentes, associado ao fato de algumas delas serem potencialmente predadoras de animais domésticos, acaba motivando o abate indiscriminado desses animais em todo o mundo, causando inclusive depleção populacional de algumas espécies em determinadas regiões (Oliver 1958; Morris \& Morris 1965; Greene 1997; Andreu 2000; Alves et al. 2010). Nesse contexto, a redução ou extinção local, regional e global de espécies resulta em uma série de impactos negativos graves, principalmente na cadeia alimentar (Gibbons 2000; Seburn \& Seburn 2000; Schlaepfer et al. 2005). O decréscimo das populações de serpentes pode gerar um descontrole das populações de roedores causadores de pragas, trazendo prejuízos à saúde humana, agricultura e cadeia alimentar silvestre. Não obstante, potenciais estudos sobre a ação farmacológica de toxinas podem ser prejudicados. Além disso, a retirada de serpentes ofiófagas pode causar aumento das populações de serpentes peçonhentas (Lima-Verde 1994).

Esses problemas se agravam quando aliados a outros fatores como a perda e fragmentação de hábitat, introdução de espécies exóticas predadoras ou competidoras, atropelamentos, mudanças climáticas, epidemias, utilização de pesticidas, contaminação da base alimentar e tráfico internacional de espécies utilizadas como pets (Lima-Verde 1994; Seburn \& Seburn 2000; Shine \& Koenig 2001; Bernarde 2004; Tolson \& Henderson 2006).

Esse trabalho teve por objetivo realizar um levantamento etnográfico sobre as crenças envolvendo o grupo dos ofídios no estado do Ceará, Nordeste do Brasil, e efetuar inferências científicas sobre cada uma delas, desmistificando-as quando necessário e procurando os fatos que possam explicar suas respectivas origens. Dessa forma, pretende-se fornecer subsídio para projetos de educação ambiental visando a diminuição da mortandade desses animais e para maior divulgação da prevenção e tratamento adequado para casos de ofidismo.

\section{MÉTodos}

Áreas de estudo. Foram selecionadas 10 localidades de nove municípios pertencentes a diferentes áreas geográficas do Ceará (serrana, sertaneja e litorânea). As localidades abordadas em cada área são adjacentes entre si (Figura 1).

$\mathrm{Na}$ área serrana, foram abordadas as zonas rurais e urbanas dos municípios de Aratuba (04²4'48.85"S,

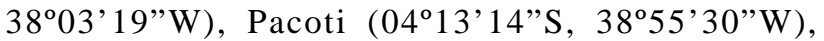
Guaramiranga $\left(04^{\circ} 16^{\prime} 17^{\prime \prime} \mathrm{S}, 38^{\circ} 55^{\prime} 56^{\prime \prime} \mathrm{W}\right)$ e Mulungu (04¹8'12”'S, 38 59'33'W), todos inclusos na Serra de Baturité, maior e mais representativo relevo residual cristalino do Ceará (Mantovani 2007). Considerada um remanescente de Mata Attântica, a Serra de Baturité é a mata úmida de maior riqueza biológica no estado, com grande importância na manutenção da biodiversidade e recursos hídricos. Possui uma grande heterogeneidade de climas, indo do super-úmido ao úmido, sub-úmido e semiárido, em função da face de exposição em relação ao mar e da variação da altitude. Devido a essas características, encontra-se incluída como Área de Proteção Ambiental, de jurisdição estadual, que abrange os municípios de Aratuba, Baturité, Capistrano, Caridade, Guaramiranga, Mulungu, Pacoti e Redenção (Mantovani 2007).

Os municípios escolhidos para representar a área sertaneja foram Itapajé ( $03^{\circ} 41^{\prime} 04.58^{\prime}$ 'S, $\left.39^{\circ} 35^{\prime} 34.48^{\prime \prime} \mathrm{W}\right)$, Tururu $\left(03^{\circ} 35^{\prime} 11.46^{\prime \prime} \mathrm{S}, 39^{\circ} 26^{\prime} 44.10^{\prime \prime} \mathrm{W}\right)$ e Irauçuba (03⒋ $57.19^{\prime \prime}$ 'S, 39 $\left.46^{\prime} 49.86^{\prime \prime} \mathrm{W}\right)$, que fazem parte da microrregião de Uruburetama, característica do complexo cristalino cearense. A área de Itapajé, apesar de abranger resquícios de floresta subperenifólia tropical pluvio-nebular, abrange também domínios de subcaducifólia tropical pluvial 


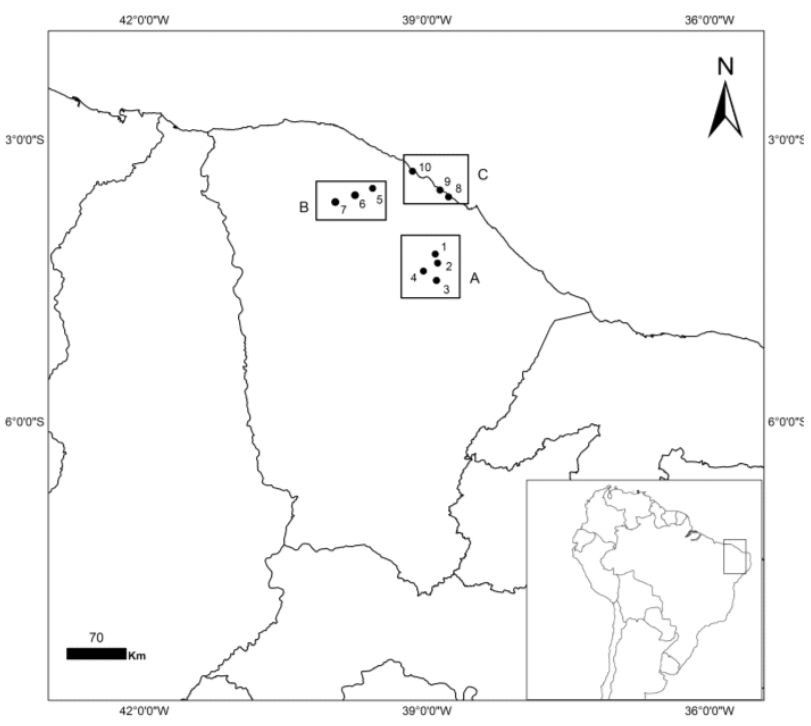

Figura 1. Mapa cartográfico das localidades abordadas, Ceará. Aárea serrana; B- área sertaneja; C- área litorânea; 1- Pacoti; 2 Guaramiranga; 3- Mulungu; 4- Aratuba; 5- Tururu; 6- Itapagé; 7Irauçuba; 8- Praia do Cumbuco, Caucaia; 9- Lagoa do Barro, Caucaia; 10- Praia da Taíba, São Gonçalo do Amarante.

e de caatinga densa. Irauçuba e Tururu possuem características morfoclimáticas absolutamente típicas do sertão cearense, com clima tropical semiárido, baixos índices de precipitação e áreas com domínios completos de caatinga densa.

As localidades litorâneas abordadas nessa pesquisa foram a Praia de Cumbuco (03³7'46.23'’S, 3844'13.24'W) e a comunidade da Lagoa do Barro (0328'20.88"S, 38 44'31.31' 'W), pertencentes ao município de Caucaia, e a Praia da Taíba (03³0’48.56”S, 3855'27.52”W), pertencente ao município de São Gonçalo do Amarante. Localizada no litoral oeste do estado, essa região é caracterizada pela formação de dunas móveis, aluviões e paleodunas, típicos da Planície litorânea, margeada pelo complexo vegetacional presente nos tabuleiros pré-litorâneos de sedimentos do Grupo Barreiras (FIPC 1989; IBGE 2011).

Coleta de dados etnozoológicos. Os entrevistados foram selecionados através da técnica snowball (Bailey 1994). A amostragem foi não-aleatória intencional, na qual foram pré-definidos os entrevistados (Albuquerque \& Lucena 2004), que consistiram de moradores que interagem de alguma maneira com a herpetofauna fauna local. Foram identificados e entrevistados 170 "especialistas locais" (Tabela 1) (e.g., caçadores, mateiros, agricultores), pessoas que se autorreconhecem e que são reconhecidas pela própria comunidade como culturalmente competentes (Hays 1976; Marques 2002). Os levantamentos nas áreas sertaneja e litorânea foram feitos mais intensamente durante o segundo semestre de 2008, através de visitas mensais constantes e, durante os anos de 2009 e 2010, através de visitas trimestrais. A pesquisa na área serrana se deu de forma mais recorrente, já que foram realizadas ali diversas expedições entre os anos de 2008 e 2010. Durante cinco meses, o pesquisador
Tabela 1. Comunidades visitadas e o respectivo número de informantes entrevistados ( $\mathrm{N}^{\mathrm{o}}$ Inf.) em cada uma.

\begin{tabular}{lc} 
Localidade & $\mathbf{N}^{\mathbf{0}}$ Inf. \\
Região sertaneja & \\
Itapajé & 10 \\
Tururu & 10 \\
Irauçuba & 10 \\
Região litorânea & \\
Praia do Cumbuco & 10 \\
Lagoa do Barro & 10 \\
Praia da Taíba & 10 \\
Região serrana & \\
Guaramiranga & 21 \\
Pacoti & 15 \\
Mulungu & 32 \\
Aratuba & 42 \\
\hline
\end{tabular}

principal ficou estabelecido nas comunidades da Serra de Baturité com o objetivo de realizar pesquisas envolvendo atividades cinegéticas sobre a masto, herpeto e avifauna local. Por esse motivo, o número de informantes na área serrana é maior quando comparado às outras áreas.

As informações sobre o conhecimento acerca das serpentes de cada área foram obtidas através de questionários semiestruturados, complementadas por entrevistas livres e conversas informais (Huntington 2000), contendo perguntas referentes a quais espécies de serpentes ocorrem nas áreas. Além disso, foram investigados que tipos de conhecimento os entrevistados possuem acerca das características morfológicas, comportamentais, fisiológicas e ecológicas dos ofídios. Durante as entrevistas, foram mostrados álbuns aos informantes, contendo fotografias de espécies da ofiofauna de cada área, segundo os levantamentos de Vanzolini et al. (1980), Lima-Verde (1991) e Borges-Nojosa (2007), que serviram de base para a identificação das espécies citadas. Além disso, a fim de garantir maior precisão na identificação, nos municípios pertencentes à APA da Serra de Baturité, foram coletados indivíduos ou amostras biológicas de cada espécie citada, posteriormente tombadas na Coleção Herpetológica da Universidade Federal da Paraíba (CHUFPB). O inventário foi complementado através de registros visuais e fotográficos de espécimes encontrados ao longo de trilhas pelas matas ou no translado entre as comunidades.

\section{Resultados e Discussão}

Nas áreas abordadas, as serpentes como um todo são denominadas "cobras" e, de acordo com 77 informantes, estão inseridas em uma categoria etnotaxonômica denominada "insetos". Em todas as comunidades visitadas, 
"inseto" é qualquer animal que pode oferecer algum tipo de risco ao ser humano, como envenenamento, doenças, pragas, ataques predatórios, entre outros. A categoria "inseto", aplicada a serpentes e a outros animais nocivos, é comumente encontrada em outros estudos realizados no Brasil (Costa-Neto \& Magalhães 2007; Costa-Neto \& Pacheco 2004). Além disso, nas localidades estudadas, espécies de outros grupos zoológicos são incluídas na denominação "cobra”, por serem ápodas e possuírem corpo alongado, como os anfisbenídeos Amphisbaena polystega (Duméril, 1851), A. alba Linnaeus, 1758, e A. vermicularis Wagler, 1824, e os anfíbios Siphonops aff. paulensis (Boettger, 1892) e Chtonerpeton aff. arii (Cascon \& LimaVerde, 1994). Nas três áreas abordadas, essas cinco espécies são chamadas tanto de "cobra-de-duas-cabeças", devido à semelhança entre a região cranial e caudal, como de "cobrascegas”, pela presença de um olho vestigial.

Diversas crenças são associadas aos ofídios nas áreas pesquisadas, as quais são apresentadas a seguir e podem ser divididas em duas categorias: 1- crenças sobre serpentes em um aspecto geral e 2- crenças exclusivas a determinadas espécies.

\section{Crenças sobre Serpentes: aspectos gerais}

Potencial letal. De modo geral, há uma tendência por parte da população rural brasileira em considerar toda serpente como peçonhenta (Vizzoto 2003). Esse fato foi constatado nesse estudo em conversas informais com moradores locais não indicados como "especialistas locais". Esses últimos, no entanto, diferenciam as serpentes entre "cobras com ou sem veneno".

Corroborando os dados zoológicos, todos os entrevistados apontam como peçonhentas e potencialmente letais ao homem os viperídeos Crotalus durissus Linnaeus, 1758 (cascavel), Bothropoides erythromelas (Amaral, 1983) (jararaca) e Lachesis muta (Linnaeus, 1766) (surucucu), serpentes de dentição solenóglifa, cujas presas inoculadoras grandes e retráteis são conectadas à glândula de veneno (Melgarejo 2003; Campbell \& Lamar 2004). Também corroborando a literatura científica, apontaram os elapídeos Micrurus ibiboboca (Merrem, 1820) (coral) e Micrurus lemniscatus (Linnaues, 1758) (coral), de dentição proteróglifa, com presas anteriores pequenas e fixas conectados à glândula venenosa (Melgarejo 2003; Campbell \& Lamar 2004).

Em discordância com estudos biológicos, os informantes atribuem como "venenosas" e causadoras de morte ao ser humano algumas serpentes da Família Colubridae: Drymarchon corais (Boie, 1927) (papa-ova), Leptophis ahaetulla (Linnaeus, 1758) (jericoá), Oxybelis aeneus (Wagler, 1824) (cobra-cipó), Pseustes sulphureus (Wagler, 1824) (papa-ova), Spillotes pulatus (Linnaeus, 1758) (caninana) e Tantilla melanocephala (Linnaeus, 1758) (cobra-rainha) e da Família Dipsadidae: Oxyrhopus trigeminus Duméril, Bibron \& Duméril, 1854 (coral),
Oxyrhopus guibei Hoge \& Romano, 1977 (coral), Thamnodynastes spp. (Linnaeus, 1758) (jararaca) e Xenodon merremi (Wagler, 1824) (boipeva). Essas serpentes possuem dois tipos de dentição: 1- áglifa, que não possui presas inoculadoras nem glândulas de veneno e 2- opistóglifa, que possui dentes posteriores modificados responsáveis pelo escorrimento de substâncias ativas provenientes de estruturas denominadas glândulas de Duvernoy (Zug et al. 2001; Melgarejo 2003). Apesar de certas serpentes opistóglifas apresentarem danos à saúde humana, chegando inclusive a alguns casos isolados de morte (Puorto \& França 2003), as únicas espécies que geralmente oferecem risco de letalidade aos seres humanos no Neotrópico são as da família Elapidae e Viperidae (Campbell \& Lamar 2004).

Além disso, Epicrates assisi (Linnaeus, 1758) (salamanta), da Família Boidae, que possui dentição áglifa, portanto não peçonhenta, foi apontada como a "cobra mais perigosa de todas", pois, segundo os informantes, é "a cobra com o pior veneno que tem, porque é a que mata mais rápido”. O temor que essa espécie causa à população local, principalmente no Semiárido, provavelmente a região de maior abundância da espécie no estado, parece superar o causado por espécies realmente peçonhentas.

Acidentes ofídicos. É importante salientar que todos os entrevistados demonstraram conhecimento da existência e da prioridade de uso do soro antiofídico em caso de acidentes. Porém, eles consideram outros procedimentos como eficazes (Figura 2). Segundo os informantes, ingerir grande quantidade de bebida alcoólica após o acidente garante retardo e até anulação da ação do veneno $(n=73$ citações). Na realidade, esse procedimento pode ter efeito contrário, uma vez que o álcool pode desidratar os tecidos sanguíneos, dificultando assim a ação do sistema imunológico contra a peçonha, além de aumentar a pressão sanguínea, facilitando a disseminação mais rápida do veneno na circulação. Outras formas de tratamento citadas pelos entrevistados, como cortar o local da picada ou mordedura para escorrer o sangue com o veneno ( $n=62$ citações), cobrir o local da picada com fumo $(\mathrm{n}=31)$, pólvora $(\mathrm{n}=17)$ ou couro de guaxinim [Procyon cancrivorus (Cuvier, 1798)] $(\mathrm{n}=22)$ e sugar o veneno $(\mathrm{n}=55)$ também são medidas inadequadas, devido ao risco de proliferação bacteriana na injúria.

O uso de torniquete acima do local da picada também foi citado ( $n=39$ ), ação também considerada como inapropriada, já que, segundo Araújo et al. (2003), aproximadamente $90,5 \%$ dos acidentes ofídicos no Brasil são botrópicos (correspondente aos gêneros Bothrops, Bothropoides, Bothriopsis, Bothrocophias e Rhinocerophis). Devido ao veneno botrópico ser de ação necrosante com consequente lesão tecidual, tal procedimento pode diminuir a irrigação sanguínea do membro atingido, causando hipoxia nos tecidos, concentrando o veneno na região oposta ao torniquete, onde há grande risco de destruição do tecido na região da 


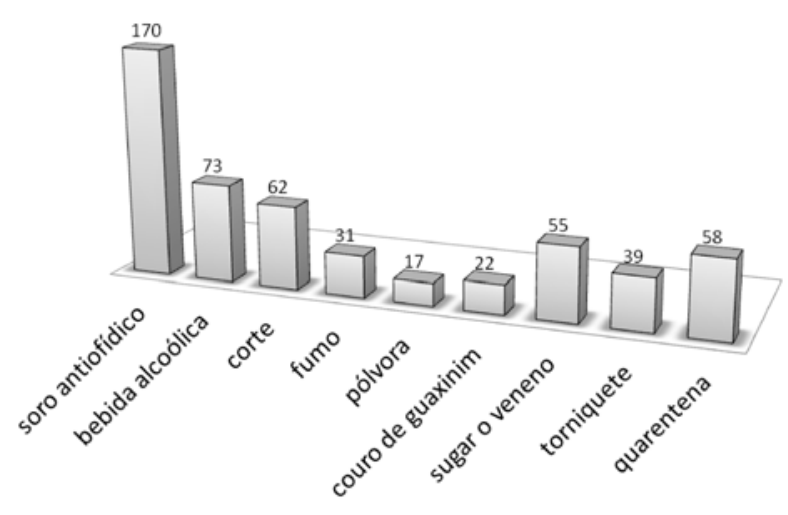

Figura 2. Métodos de tratamento para acidentes ofídicos e seus respectivos números de citações em todas as comunidades abordadas.

picada.

Todas essas formas de tratamento citadas são bastante comuns no Brasil (Vizzoto 2003) e, infelizmente, alguns procedimentos, como o uso do torniquete, são citados como eficazes inclusive em livros didáticos escolares, como apontam Sandrin et al. (2005). Outro relato comum ( $n=58$ citações) foi a recomendação de repouso total durante 40 dias (quarentena), onde o paciente não poderia estabelecer qualquer tipo de contato verbal, nem sequer ouvir o chamarem pelo nome e muito menos ouvir falarem sobre seu acidente, sob o risco da ação do veneno se intensificar.

Esses tipos de procedimentos são considerados como inadequados pelo Ministério da Saúde (2001), que postula que as medidas apropriadas em caso de acidentes ofídicos são: 1- manter o paciente calmo e, se possível, em repouso; 2- retirar anéis, pulseiras e outros objetos constritores; 3limpar cuidadosamente o local com água e sabão; 4- manter o paciente hidratado; 5- encaminhar o paciente o mais rápido possível para um centro de atendimento.

Nesse contexto, é válido ressaltar que procedimentos utilizados na medicina popular adquirem créditos de eficácia pelas comunidades rurais e tradicionais brasileiras, possivelmente por serem utilizados em situações onde não há envenenamento ou quadro patológico preocupante (Puorto \& França 2003). No Brasil, das 375 espécies de ofídios documentadas (Bérnils \& Costa 2011), apenas são consideradas peçonhentas com risco letal as dos gêneros Bothrops, Bothropoides, Bothrocophias, Bothriopsis, Crotalus, Lachesis e Rhinocerophis, da família Viperidae, e Leptomicrurus e Micrurus, da família Elapidae, totalizando 55 espécies. Já que acidentes ofídicos podem envolver praticamente qualquer espécie de serpente, a possibilidade de ocorrências provocadas por espécies não-peçonhentas é alta. Além disso, apenas cerca de $20 \%$ dos acidentes provocados por espécies peçonhentas envolve envenenamento e somente $50 \%$ dos acidentes nos quais ocorrem envenenamento resulta em algum problema grave (Lima-Verde 1994). Apesar do número de acidentes ofídicos no Brasil se manter há décadas em torno de 20.000 por ano, o índice atual de óbito, graças a programas governamentais de produção e distribuição de antídoto, se dá em cerca de 1\% (Araújo et al. 2003).

Os informantes também relataram que vítimas de acidentes ofídicos, mesmo quando tratadas, passam o restante da vida enfermas ( $n=33$ citações). Outros afirmam que os sintomas do envenenamento reaparecem em cada fase de Lua correspondente àquela da época do acidente (n $=24$ citações) e outros ainda relatam que uma vez picado por uma serpente, o organismo pode adquirir imunidade à peçonha ( $n=29$ citações). A imunidade ao veneno também é relacionada às pessoas que nascem em dia de domingo (n = 31) ou que possuem os sulcos da palma da mão em formato estrelar $(n=22)$. No entanto, é importante salientar que os sintomas apresentados por vítimas de acidentes peçonhentos variam de acordo com a espécie da serpente responsável. Os venenos botrópicos (provenientes dos gêneros Bothrops, Bothropoides, Bothriopsis, Bothrocophias e Rhinocerophis) e laquéticos (gênero Lachesis) possuem principalmente ação proteolítica, coagulante e hemorrágica (França \& Málaque 2003; Málaque \& França 2003); enquanto os crotálicos (gênero Crotalus) têm ação miotóxica, neurotóxica e coagulante (AzevedoMarques et al. 2003) e os elapídicos (gêneros Leptomicrurus e Micrurus) apresentam ações neurotóxica e miotóxica (Silva-Júnior \& Bucaretchi 2003). Nenhuma dessas ações é permanente ou possui capacidade de reincidir depois de meses, pois o veneno ofídico é composto por substâncias protéicas, portanto sujeitas à fácil desnaturação e degradação. Contudo, dependendo da gravidade, a vítima pode sofrer sérios comprometimentos das funções renais e motoras. Além disso, em vias de regra, o organismo humano não é capaz de produzir anticorpos capazes de neutralizar uma nova injeção venenosa.

\section{Crenças sobre Determinadas Espécies de Serpentes}

Boa constrictor Linnaeus, 1758. Boídeo, que subjulga suas presas por constricção, possui hábitos diurnos e noturnos, preferência alimentar por mamíferos e aves e pode chegar a $4 \mathrm{~m}$ de comprimento (Vanzolini et al. 1980). Nas três áreas abordadas, é chamada de "cobra-deveado".

"Cobra-de-veado mata quebrando osso." Relatos das três áreas abordadas constam que a cobra-de-veado, ao desferir o bote constritor em uma presa, quebra-lhe os ossos, para depois ingeri-la $(n=84$ citações $)$. Tal crença, tanto relacionada a essa espécie como também para outros boídeos, como os do gênero Eunectes e Python, é bastante difundida em todo o Brasil (Vizotto 2003) e no mundo (Oliver 1958; Morris \& Morris 1965; Andreu 2000; Vizotto 2003).

"Cobra-de-veado berra para chamar chuva." Crença da área litorânea semelhante à encontrada na área serrana para a Lachesis muta (surucucu), que reza que a serpente emite sons semelhantes aos de um bezerro, para atrair chuva ( $n=37$ citações).

Todas as serpentes constrictoras, melhor 
representadas pela família Boidae, subjulgam suas presas apenas por asfixia (Morris \& Morris 1965). Caso a $B$. constrictor tivesse a capacidade de quebrar ossos, as pontas formadas pelas fraturas facilmente poderiam rasgar seu estreito trato digestivo. Quanto à segunda crença, ela possivelmente foi originada devido aos silvos que essa espécie emite, formados pela liberação de ar dos pulmões de encontro ao estreitamento traqueal e que podem ser escutados a até $6 \mathrm{~m}$ de distância (Vizotto 2003), mas que não possui relação com período de chuva e sim com situações de estresse.

Epicrates assisi (Linnaeus, 1758). Boídeo que apresenta hábitos diurnos e noturnos e coloração dorsal iridescente, quando exposta à luz. Alimenta-se principalmente de mamíferos e aves e possui hábito semiarborícola (Vanzolini et al. 1980). Nas três áreas, tem o nome vernacular de salamanta ou saramanta.

"Salamanta muda de cor." Os entrevistados da área sertaneja afirmam que em situações de perigo ou com o avanço da idade, a salamanta muda sua coloração dorsal (n $=24$ citações )

"Salamanta pica e levanta a cabeça pra escutar a queda." Além da afirmação de que a espécie E. assisi seria de alta periculosidade letal, alguns informantes da área serrana ainda completam que ela possui tão má índole, que acompanha a vítima de seu bote até obter a certeza da morte, levantando a cabeça para escutar o tombo $(n=25)$.

Em relação à mudança de coloração, a origem dessa crença provavelmente se deve ao potencial de iridescência observada na camada ectodérmica dessa espécie, que reflete a luz solar em cores apostemáticas. Com relação à outra crença, além de todas as serpentes serem desprovidas de aparelho auditivo (Zug et al. 2001, Greene 1997) e dessa espécie ser áglifa e não-peçonhenta, nenhum ofídio tem como comportamento verificar a morte de sua vítima, em situações de defesa. Os viperídeos, de maneira geral, desferem seu bote em uma presa e, geralmente, soltam centésimos de segundos depois. Após a morte do animal, decorrente da ação citotóxica e proteolítica do veneno, as serpentes se direcionam até a presa para sua posterior ingestão, porém, exclusivamente em situações de predação (Campbell \& Lamar 2004).

Crotalus durissus Linnaeus, 1758. Viperídeo de hábitos noturnos, preferência alimentar por pequenos mamíferos, dorso castanho, com losangos sequenciais mais claros e um guizo, formado pela deposição de ecdises na extremidade caudal (Klauber 1972; Vanzolini et al. 1980). Nas três áreas abordadas, é popularmente denominada cascavel.

"Cada anel do chocalho da cascavel é um ano de idade que ela tem." Crença da área serrana e sertaneja, que consiste na afirmação de que cada anel que compõe o chocalho da cascavel corresponde a um ano de vida da serpente ( $n=48$ citações $)$.

"Cascavel mata filhote que não dá bote." Segundo os entrevistados da área sertaneja, a fêmea de Crotalus durissus dispõe seus filhotes em uma linha de frente e aniquila aqueles que não reagirem contra seus ataques, comendo-os $(\mathrm{n}=11)$.

"Quem mija em cima de esqueleto de cascavel, morre." Os informantes da área sertaneja contam que, ao matarem uma cascavel, a enterram numa cova e colocam sobre ela dois tijolos a fim de sinalizarem o local, para que ninguém urine sobre ele, sob o risco do veneno da serpente subir pela urina e atingir a vítima $(\mathrm{n}=11)$.

"Pra matar cascavel, tem que ser pela cabeça, porque se você cortar ela no meio, ela vive como um cotoco de cobra." Na Serra de Baturité, Crotalus durissus é encontrada com maior frequência na face sotavento do maciço, de clima mais seco e vegetação mais aberta, devido à influência do bioma da Caatinga adjacente (Borges-Nojosa 2007). Na Aldeia dos Fernandes (Aratuba), localizada na face sotavento da serra, os nativos, descendentes de índios da tribo Canindé, afirmam que "cotocos de cascavéis" esporadicamente são encontrados no vilarejo, principalmente em lavouras, trazendo perigo à comunidade. Eles relatam que esses “cotocos” são, na realidade, cascavéis vítimas de golpes desferidos por pessoas que as cortaram pela metade. Eles recomendam que, ao se deparar com essa espécie, deve-se deflagrar o golpe na cabeça, pois, caso contrário, a metade anterior da cobra sobrevive $(\mathrm{n}=10$ citações).

"Quem pisa no esqueleto de cascavel morta, se envenena." Crença exclusiva da área sertaneja ( $n=14$ citações), que afirma que, se alguém pisar em esqueleto de serpente peçonhenta, sofrerá os males tais quais os de uma picada.

"Pra deixar cascavel parada tem que dar nó na camisa." Crença atribuída à cascavel na área sertaneja (n= 14 citações), mas também a todas as serpentes consideradas como peçonhentas pela população local das áreas serrana $(n=13)$ e litorânea $(n=6)$. Para evitar que a serpente se mova para desferir o bote, os informantes afirmam dar um nó com a base da camisa com que estão vestidos, fogem e geralmente voltam ou mandam alguém para matar o animal, o qual, segundo eles, ainda estará imóvel no mesmo local.

A origem para a primeira crença, comum no continente americano (Andreu 2000; Vizotto 2003; Sandrin et al. 2005), é explicada através da relação que o sertanejo faz entre o tamanho da serpente e o número de anéis do chocalho, que realmente é diretamente proporcional e dependente de fatores temporais. No entanto, a formação de cada anel se dá através da deposição de segmentos de queratina na extremidade da cauda, a cada ecdise, caracterizada pelo fenômeno da troca da camada tegumentar, a qual normalmente se desprende de uma região proximal dos lábios, prossegue liberando-se da placa córnea e avança, através de fricção com superfícies ásperas, desvencilhandose da pele até a cauda (Klauber 1972). Para a cascavel, a ecdise pode ocorrer entre duas a quatro vezes por ano, 
dependendo da disponibilidade de alimento e de fatores ambientais e, além disso, é possível que o chocalho quebre ao se chocar com materiais mais resistentes (Sandrin et al. 2005).

Nenhum registro bibliográfico pesquisado confirma o comportamento de aniquilamento de filhotes por $C$. durissus. $\mathrm{Na}$ caatinga cearense, existem algumas serpentes que são ofiófagas, como a Pseudoboa nigra (Duméril, Bibron \& Duméril, 1854), Micrurus ibiboboca e Drymarchon corais (Vanzolini et. al 1980; Lima-Verde 1991), o que provavelmente pode ter originado a segunda crença.

Quanto à terceira crença, além do envenenamento ser dependente do contato da vítima com a presa inoculadora, a crotoxina é um composto protéico (Klauber 1972) e que portanto degrada-se facilmente com a ação ambiental pósmorte e, obviamente, não possui nenhuma propriedade antigravidade que faça com que ele suba através da urina.

Os órgãos vitais, como pulmão, estômago, gônadas, fígado e intestino das serpentes são alongados e distribuídos pelo corpo (Seigel et al. 1987), portanto, um golpe que consiga cortá-las ao meio irá com total certeza levá-las a óbito. Nesse contexto, a origem da quarta crença pode ser explicada tomando como base dois fatores relacionados à perda do principal referencial da cauda da cascavel, o guizo. O primeiro é que, como relatado anteriormente, as cascavéis podem perder seu chocalho, através do choque brusco com algum material mais resistente. Além disso, indivíduos recém natos não possuem o guizo. Esse último fator ainda é mais consistente, por se tratar de indivíduos de comprimento curto e, portanto, possivelmente confundidos com "cotocos". Porém, ainda há um terceiro fator, relativo a uma possível confusão entre espécies, pois o temor instantâneo causado pelo encontro com uma serpente pode dificultar a identificação. Alguns indivíduos de Bothropoides erythromelas (Amaral, 1923), também da Família Viperidae e indivíduos jovens de Xenodon merremii (Wagler, 1824) (Família Dipsadidae), podem ser confundidos com cascavéis pequenas sem chocalho ou com "cotocos de cascavel”, por possuírem tamanho pequeno, semelhança morfológica e hábitat compartilhados com Crotalus durissus.

Com relação à quinta crença, todas as serpentes peçonhentas possuem veneno armazenado apenas em glândulas localizadas na região bucal, o qual escorre através de presas que, no caso da Crotalus durissus, são retráteis e se localizam na parte anterior da mandíbula superior (Klauber 1972). Sendo assim, o contato com vértebras e costelas está completamente livre de perigo quanto a riscos de envenenamento. Entretanto, pisar em uma espécie peçonhenta, mesmo morta, pode realmente resultar em acidente grave, pois quando uma serpente morre, é possível que ela antes se contorça e permaneça de ventre para cima, geralmente com a boca aberta. Isso faz com que suas presas, as quais ainda podem conter veneno desidratado em seus canais, fiquem à mostra, possibilitando um acidente. Além disso, pessoas que se ferem com estruturas ósseas que contenham restos de material orgânico em decomposição estão sujeitas a infecções causadas por fungos e bactérias (Vizotto 2003).

Quanto à última crença, ocorrências como essa acontecem principalmente no período diurno, quando os nativos estão realizando suas atividades de pecuária e agricultura. É fundamental elucidar que as serpentes peçonhentas da família Viperidae, entre outras espécies, realizam suas atividades de forrageamento e busca de presas no período noturno, enquanto que, no período diurno, permanecem geralmente imóveis, porque passam a maior parte do tempo em repouso (Campbell \& Lamar 2004). Outro motivo é que a postura de imobilidade é uma estratégia de defesa primordial de diversas espécies (Zug 2001).

Lachesis muta (Linnaeus, 1766). Viperídeo de grande porte, potencialmente peçonhento e que pode chegar a 3,5 m de comprimento. Possui coloração amarelo-escura, com machas losangulares negras ao longo do dorso e ventrais brancas, hábitos noturnos, preferência alimentar por pequenos mamíferos e vive principalmente em domínios florestais úmidos. (Lima-Verde 1991; Zamudio \& Greene 2008). No estado do Ceará, ocorre exclusivamente na Serra de Baturité (Borges-Nojosa \& Lima-Verde 1999), onde é chamada de surucucu, malha-de-fogo e pico-de-jaca. Pelo seu nível de endemismo, só recebeu citações nessa área.

"Surucucu canta quando vai chover." Uma das crenças mais comuns da área serrana, em que a Lachesis muta cantaria ou berraria em alto volume, lembrando um uivo curto de um canídeo, quando vai chover ou com o propósito de chamar chuva. Segundo os relatos, quando um indivíduo canta em algum local, outros respondem em locais mais distantes $(\mathrm{n}=30$ citações $)$.

"Surucucu tem raiva de fogo." Ao se deparar com uma fogueira ou qualquer objeto incandescente, os entrevistados afirmam que a surucucu aparece com uma fúria incontrolável e desfere incontáveis botes às chamas a fim de apagá-las, chegando ocasionalmente a morrer carbonizada. Essa crença foi atribuída por Vizzoto (2003) como comum em áreas da Amazônia e Mata Atlântica ( $\mathrm{n}=$ 30 citações).

Devido à ausência de cordas vocais ou qualquer outra estrutura análoga, essa espécie provavelmente não consegue emitir sons, nem mesmo expelindo ar dos pulmões, como faz a Boa constrictor. A única produção sonora realizada por essa espécie é através do batimento contínuo e acelerado da ponta da cauda queratinizada no solo, quando em situação de estresse. Mesmo se o contrário fosse possível, a probabilidade de resposta ao canto seria nula, devido à ausência de orifícios auditivos. Quanto à irritabilidade ao fogo, esse fato provavelmente pode ser concreto, porém não com todas as características presentes no imaginário popular. Segundo Vizotto (2003), o renomado herpetólogo Dr. Alphonse Hoge, em comunicação pessoal com outros pesquisadores, relatou que, ao ligar os 
aquecedores da Seção de Herpetologia do Instituto Butantan, observava que "as surucucus perdiam sua docilidade habitual e davam botes contra o vidro, em direção de onde provinha o calor." As surucucus possuem um par de fossetas loreais, responsáveis pela termorrecepção, provavelmente as mais sensíveis dos crotalíneos (Vizotto 2003), que consegue perceber variações de até $0,003^{\circ} \mathrm{C}$ (Melgarejo 2003).

Micrurus ibiboboca (Merrem, 1820). Elapídeo de cabeça não destacada do corpo, coloração em tríades anelares completas vermelhas, brancas e negras, hábitos noturnos, crepusculares ou diurnos, alimentação primordialmente ofiófaga, dentição proteróglifa, portanto, potencialmente peçonhento (Lima-Verde 1991; Melgarejo 2003). Em todas as áreas, é chamada de coral.

"Quem é picado por coral, bota sangue pelos ouvidos, pelos olhos, pela boca..." É comum a todas as áreas abordadas o relato de que, logo após um acidente causado pela coral, ocorre sangramento das vias nasais, oculares, bucais e anais ( $\mathrm{n}=65$ citações).

De acordo com Silva-Jr. \& Bucaretchi (2003), a ação hemorrágica visceral, pulmonar e subendocárdica do veneno elapídico, que possui primordialmente ação neurotóxica, foi demonstrada experimentalmente em ratos, mas nunca evidenciado em humanos.

Oxybelis aeneus (Wagler, 1824). Colubrídeo de médio porte, que pode chegar a até $1 \mathrm{~m}$ de comprimento, com cabeça alongada e corpo bastante delgado, com coloração dorsal pardo acinzentada, com finas estriações brancas. Alimentase de lagartos e possui hábito arborícola, onde facilmente é confundida com a vegetação (Vanzolini et al. 1980). Quando em situações de estresse, abre a boca e mostra sua cavidade interna negra, para afugentar possíveis predadores. Nas três áreas, tem nomenclatura popular de cobra-cipó.

"Quem morde cobra-cipó, quando confunde com um galho, morre." Ao se emaranhar com galhos secos durante travessias pela mata, entrevistados da área sertaneja relatam que, ao tentarem se livrar e arrancar um desses galhos com os dentes, para poderem continuar seu caminho, eles podem não perceber que aquele galho trata-se na verdade de uma cobra-cipó e então estarão fadados ao envenenamento e morte imediata ( $\mathrm{n}=21$ citações).

"Cobra-cipó muda de cor." Na área litorânea, há a crença de que essa serpente possa mudar sua coloração, de acordo com a vegetação ( $\mathrm{n}=19$ citações).

"Picada de cobra-cipó deixa a vítima fina que nem cobra." Em todas as áreas, é atribuída à cobra-cipó a crença de que sua picada deixa a vítima com aparência raquítica, semelhante a do ofídio $(n=34)$.

É impossível qualquer envenenamento ofídico através de algum processo que não seja pelo contato da presa inoculadora com a vítima. Além disso, apesar dessa espécie produzir veneno, sua ação não tem potencial letal suficiente para o ser humano. Porém, ela possui uma reação de defesa bastante agressiva, expondo sua cavidade bucal de cor negra e realizando repetidos botes secos, o que pode gerar assimilações errôneas, sobre o seu grau de periculosidade. A segunda crença possivelmente foi gerada devido à característica anatômica dessa espécie, que possui padrão de mimetismo com os ramos e galhos da mata seca e, apesar de possuir alguma variação de coloração entre indivíduos, não possui potencial individual de alteração de cor de acordo com o substrato. Quanto à terceira crença, apesar de alguns colubrídeos oferecerem perigo à saúde humana, podendo causar dor, sangramento, eritema, edema e equimose (Puorto \& França 2003), não existe registro de que o veneno de qualquer serpente estimule perda massiva de massa muscular ou adiposa.

Pseudoboa nigra (Duméril, Bibron \& Duméril, 1854). Colubrídeo de médio porte, de dentição opistóglifa. $\mathrm{O}$ indivíduo adulto apresenta coloração dorsal negra e ventral branca, possui hábito noturno e terrícola e alimentase preferencialmente de lagartos e de alguns ofídios (LimaVerde 1991; Orofino et al. 2010). Alguns indivíduos podem apresentar machas brancas irregulares no dorso. Nas três áreas, é denominada cobra-preta e, na área sertaneja, também é chamada de cobra-de-leite.

"Cobra-preta / Cobra-de-leite mama em mulher grávida." Serpentes que mamam é uma crença amplamente difundida em todo o território brasileiro, quase toda a América Latina, parte da Europa e Norte da África (Andreu 2000; Vizotto 2003). As espécies variam de acordo com a região, mas a crença é praticamente a mesma em todas elas. Nesse trabalho, a espécie responsável por tal fato é a Pseudoboa nigra, denominada cobra-de-leite e cobra-preta. Segundo os informantes de todas as áreas abordadas, a cobra-preta aproxima-se da mulher em fase de lactação, quando ela está dormindo e amamentando, ocupa o lugar da criança e, atenta para que essa não a perceba, coloca a ponta da cauda em sua boca. O imaginário popular registrado nesse trabalho vai ainda mais além, pois alguns entrevistados citam que, quanto mais leite a cobra-preta ingere, maior será a quantidade de manchas brancas no seu dorso ( $\mathrm{n}=77$ citações).

Não há serpentes que possuam o hábito de ingerir leite. Além de não fazer parte da dieta, o exercício de sucção seria impossível, devido à ausência do músculo esfíncter bucal. A origem para tal crença, segundo Vizotto (2003), pode ser explicada, já que o aniquilamento de uma serpente é geralmente realizado através de golpes de pedaços de madeira ou instrumentos agrícolas, dilacerando-a, fazendo com que se extravase um líquido espesso branco, com aspecto de leite coalhado. Esse líquido pode ser fruto do processamento metabólico da digestão do cálcio, proveniente das presas que, ao juntar-se com o restante do material excretado, resulta em dejetos chamados de urato, com coloração que lembra a substância láctea. Outra possível procedência é que, no período reprodutivo, os machos secretam grande quantidade de líquido albuminoide esbranquiçado, que forma parte do líquido seminal. E a última 
explicação se dá pela presença de ovos nos ovidutos de fêmeas ovígeras, os quais também apresentam substância albuminoide esbranquiçada.

Spilotes pullatus (Linnaeus, 1758). Colubrídeo de dorso negro e largas faixas amareladas irregulares na cabeça e região anterior do corpo, hábitos diurnos, arborícola e preferência alimentar por pequenos mamíferos e aves (LimaVerde 1991). Nas três áreas, é chamada de caninana.

"Caninana voa e persegue pessoas." Em todas as áreas estudadas, é atribuída à Spilotes pullatus a crença de que ela seria capaz de alçar vôos curtos do chão ou de uma árvore a outra e de que ela seria tão violenta ao ponto de perseguir um ser humano por quilômetros até alcançar o êxito de picá-lo ( $\mathrm{n}=30$ citações $)$.

"Caninana dá chicotada." Segundo os entrevistados da área litorânea, a caninana, quando acuada, prende a região da cabeça em um galho e desfere chicotadas com a ponta da cauda em quem passar por perto ( $n=12$ citações).

Essa espécie realmente é bastante irritadiça e desfere sucessivos botes àquele que resolver aproximar-se muito dela (Lima-Verde 1991), porém, nenhuma serpente tem o hábito de perseguir incansavelmente o ser humano, como muitos afirmam. O fato de ela ser arborícola e possuir exímia agilidade ao atravessar galhos de árvores e de ter padrões de bote, em que se projeta para frente e para cima justifica a origem da crença do "vôo". Além disso, nenhuma serpente é capaz de chicotear com a cauda, porém a Spilotes pullatus, assim como outras serpentes, como Lachesis muta e outros viperídeos, tem o hábito de bater a ponta da cauda contra o substrato freneticamente, como sinal de alerta, fato que pode ter originado tal crença.

\section{Considerações Finais}

A exemplo do que ocorre em todo o mundo, o temor é um fator onipresente na relação entre a população e as serpentes nas localidades pesquisadas no presente estudo. Esse sentimento possivelmente impediu durante décadas e ainda impede uma aproximação que permitiria às comunidades envolvidas um conhecimento popular que corroborasse de maneira mais consistente o conhecimento científico. Como consequência, gera-se uma variedade de crenças que difundem ainda mais essa relação antagônica entre humanos e ofídios, as quais são originadas principalmente devido a assimilações de fatos naturais observados por antepassados e transpassadas através de diversas gerações, ganhando créditos incondicionais em meio a essas comunidades.

A relação conflituosa entre humanos e serpentes promove uma justificativa leiga e massificada para o abate indiscriminado desses animais, podendo provocar depleção populacional em nível local, regional e global, principalmente quando aliado a outros fatores como perda e fragmentação de hábitat, atropelamentos, disseminação de doenças e sobre-exploração de espécies.

As áreas sertaneja e serrana abordadas possuem uma riqueza de registros etnográficos relacionados a serpentes bem maior do que a área litorânea. Esse índice pode ser explicado possivelmente pela provável não ocorrência ou, pelo menos, menor densidade de viperídeos de grande porte na área litorânea, como a cascavel (Crotalus durissus) e a surucucu (Lachesis muta). Essas espécies são responsáveis pelo maior número e maior diversidade de citações nas áreas sertaneja e serrana respectivamente, evidenciando maior aguçamento do imaginário popular quando comparado a outras espécies. Outro possível motivo é o fato de que, historicamente, a dependência econômica nessas duas áreas está muito mais ligada aos recursos provenientes da mata, aumentando as possibilidades de contato entre humanos e ofídios, em relação à área litorânea, subsidiada principalmente pelos recursos marinhos e o turismo.

Desse modo, torna-se necessária a implantação de políticas de educação ambiental para divulgar a importância das serpentes para o equilíbrio ambiental e a saúde pública. Além disso, é de grande importância um maior fomento a programas de prevenção e divulgação de procedimentos corretos para primeiros socorros e tratamento em casos de acidentes ofídicos.

\section{Agradecimentos}

Aos informantes das comunidades abordadas; à Coordenação de Aperfeiçoamento de Pessoal de Nível Superior (CAPES), pela bolsa concedida; à Família Kenney Blumer (Sítio Dez Palmeiras) e à Família Veiga (Pousada Varshana), pelo companheirismo e hospedagem; aos biólogos inatos Cleito e Gleidson Lima, e a todos os colegas que colaboraram em campo ou no fornecimento de material bibliográfico.

\section{REFERÊNCIAS}

Albuquerque, U.P. \& Lucena, R.F.P. 2004. Métodos e técnicas para coleta de dados. In: U.P. Albuquerque, R.F.P. Lucena \& L.V.F.C. Cunha (coords), Métodos e Técnicas na Pesquisa Etnobotânica. Editora Livro Rápido/NUPEEA, Recife.

Alves, R.R.N.; Pereira-Filho, G.A. \& Lima, Y.C.C. 2006. Snakes used in ethnomedicine in Northeast Brazil.
Environment, Development and Sustainability 9(4): 455-464. Alves, R.R.N.; Pereira-Filho, G.A.; Vieira, K.S.; Santana, G.G.; Vieira, W.L.S. \& Almeida, W.O. 2010. Répteis e as populações humanas no Brasil: uma abordagem etnoherpetológica. In: R.R.N. Alves, W.M. Souto \& J.S. Mourão (eds), A Etnozoologia no Brasil: importância, status 
atual e perspectivas futuras. NUPEEA, Recife.

Andreu, G.C. 2000. Mytos, leyendas y realidades de los Rrptiles de Mexico. Ciencia Ergo Sum 7(3): 286-291.

Araújo, A.M. 2004. Folclore Nacional I: festas, bailados, mitos e lendas. Martins Fontes, São Paulo.

Araújo, F.A.A., Santalúcia, M. \& Cabral, R.F. 2003. Epidemiologia dos acidentes por animais peçonhentos. In: J.L.C. Cardoso, F.O.S. França, F.H. Wen, C.M.S. Malaque \& V. Haddad-Junior (eds), Animais Peçonhentos no Brasil: biologia, clínica e terapêutica dos acidentes. Sarvier, São Paulo.

Azevedo-Marques, M.M.; Hering, S.E. \& Cupo, P. 2003. Acidente crotálico. In: J.L.C. Cardoso, F.O.S. França, F.H. Wen, C.M.S. Malaque, \& V. Haddad-Junior (eds), Animais Peçonhentos no Brasil: biologia, clínica e terapêutica dos acidentes. Sarvier, São Paulo.

Bailey, K. 1994. Methods of Social Reached. The Free Press, New York.

Bernarde, P.S. 2004. Composição Faunística, Ecologia e História Natural de Serpentes em uma Região no Sudoeste da Amazônia, Rondônia, Brasil. Tese de Doutorado. Universidade Estadual Paulista Julio de Mesquita Filho.

Bérnils, R.S. \& Costa, H.C. 2011. Brazilian Reptiles - list of species. Sociedade Brasileira de Herpetologia. Disponível em http://www.sbherpetologia.org.br/; acesso em 21 dez. 2011.

Borges-Nojosa, D.M. 2007. Diversidade de anfíbios e répteis da Serra de Baturité. In: T.S. Oliveira \& F.S. Araújo (eds), Diversidade e Conservação da Biota na Serra de Baturité, Ceará. Coelce/UFC, Fortaleza.

Borges-Nojosa, D.M. \& Lima-Verde, J.S. 1999. Lachesis muta rhombeata. Geographic distribution. Herpetological Review 30(4): 235.

Campbell, J.A. \& Lamar, W.W. 2004. The Venomous Reptiles of Western Hemisphere. Vol. 2. Cornell University Press, Ithaca and London.

Costa-Neto, E.M. \& Magalhães, H.F. 2007. The ethnocategory insect in the conception of the inhabitants of Tapera County, São Gonçalo dos Campos, Bahia, Brazil. Anais da Academia Brasileira de Ciências 79: 239-249.

Costa-Neto, E.M. \& Pacheco, J.M. 2004. A construção do domínio etnozoológico "inseto" pelos moradores do povoado de Pedra Branca, Santa Terezinha, estado da Bahia. Acta Scientiarum Biological Sciences 26(1): 81-90.

Fenwick, A.M.; Gutberlet Jr, R.L.; Evans, J.A. \& Parkinson, C.L. 2009. Morphological and molecular evidence for phylogeny and classification of South American pitvipers, genera Bothrops, Bothriopsis, and Bothrocophias (Serpentes: Viperidae). Zoological Journal of the Linnean Society 156: 617-640.

FIPC (Fundação Instituto de Planejamento do Ceará) 1989. Atlas do Ceará. FIPC, Fortaleza.

França, F.O.S. \& Málaque, C.M.S. 2003. Acidente botrópico. In: J.L.C. Cardoso, F.O.S. França, F.H. Wen, C.M.S. Malaque \& V. Haddad-Junior (eds), Animais Peçonhentos no Brasil: biologia, clínica e terapêutica dos acidentes. Sarvier, São Paulo.

Frederico, E.Y. 2003. O inferno são os outros: animais peçonhentos no Brasil Colonial. In: J.L.C. Cardoso, F.O.S. França, F.H. Wen, C.M.S. Malaque \& V. Haddad-Junior (eds), Animais Peçonhentos no Brasil: biologia, clínica e terapêutica dos acidentes. Sarvier, São Paulo.
Gibbons, J.W.; Scott, D.E.; Ryan, T.J.; Buhlmann, K.A.; Tuberville, T.D.; Metts, B.S.; Greene, J.L.; Mills, T.; Leidein, Y.; Poppy, S. \& Winne, C.T. 2000. The global declines of reptiles, déjà vu amphibians. BioScience 50(8): 653-666.

Greene, H. 1997. Snakes. The evolution of mystery in nature. University of California Press, Berkeley.

Hays, T.E. 1976. An empirical method for the identification of covert categories in ethnobiology. American Ethnologist 3(3): 489-507.

Huntington, H.P. 2000. Using traditional ecological knowledge in science: methods and applications. Ecological Applications 10: $1270-1274$.

IBGE (Instituto Brasileiro de Geografia e Estatística) 2011. Cidades do Ceará. Disponível em: http://www.ibge.gov.br/cidadesat/ topwindow.htm?1; acesso em 6 jan. 2011.

Klauber, L.M. 1972 Rattlesnakes. Vols 1 e 2.2 ed. University of California Press, Berkeley.

Lima-Verde, J.S. 1991. Estado Atual do Conhecimento sobre a Fauna Reptiliana do Ceará. Tese de Concurso para Professor Titular. Universidade Federal do Ceará.

Lima-Verde, J.S. 1994. Por que não matar as nossas cobras. In: L.B. Nascimento, A.T. Bernardes \& G.A. Cotta (eds), Herpetologia no Brasil. PUC Minas Gerais, Belo Horizonte.

Málaque, C.M.S. \& França, F.O.S. 2003. Acidente laquético. In: J.L.C. Cardoso, F.O.S. França, F.H. Wen, C.M.S. Malaque \& V. Haddad-Junior (eds), Animais Peçonhentos no Brasil: biologia, clínica e terapêutica dos acidentes. Sarvier, São Paulo.

Mantovani, W. 2007. Conservação de Biodiversidade. In: T.S. Oliveira \& F.S. Araújo (eds), Diversidade e Conservação da Biota na Serra de Baturité, Ceará. Coelce/UFC, Fortaleza.

Marques, J.G. 2001. Pescando Pescadores. NUPAUB-USP, São Paulo.

Marques, J.G. 2002. O olhar (des)multiplicado. O papel do interdisciplinar e do qualitativo na pesquisa etnobiológica e etnoecológica. In: M.C.M. Amorozo, L.C. Mingg \& S.M.P. Silva (eds), Métodos de Coleta e Análise de Dados em Etnobiologia, Etnoecologia e Disciplinas Correlatas. UNESP/ CNPq, Rio Claro.

Melgarejo, A.R. 2003. Serpentes Peçonhentas do Brasil. In: J.L.C. Cardoso, F.O.S. França, F.H. Wen, C.M.S. Malaque \& V. Haddad-Junior (eds), Animais Peçonhentos no Brasil: biologia, clínica e terapêutica dos acidentes. Sarvier, São Paulo.

Ministério da Saúde 2001. Manual de Diagnóstico e Tratamento de Acidentes por Animais Peçonhentos. Fundação Nacional de Saúde (Funasa), Brasília.

Morris, R. \& Morris, D. 1965. Men and Snakes. Hutchinson, London.

Nomura, H. 1996. Os Répteis no Folclore. Coleção Mossoroense, Série "C". Vol. 893. ETFRN-UNED de Mossoró e Secretaria de Educação, Cultura e Desporto do RN, Mossoró.

Oliver, J.A. 1958. Snakes in Fact and Fiction. The Macmillian Company, New York.

Orofino, R.P.; Pizzatto, L. \& Marques, O.A.V. 2010. Reproductive biology and food habits of Pseudoboa nigra (Serpentes, Dipsadidae) from the Brazilian cerrado. Phyllomedusa 9: 53-61.

Puorto, G \& França, F.O.S. 2003. Serpentes não peçonhentas e aspectos clínicos dos acidentes. In: J.L.C. Cardoso, F.O.S. 
França, F.H. Wen, C.M.S. Malaque \& V. Haddad-Junior (eds), Animais Peçonhentos no Brasil: biologia, clínica e terapêutica dos acidentes. Sarvier, São Paulo.

Sandrin, M.F.N., Puorto, G. \& Nardi, R. 2005. Serpentes e acidentes ofídicos: um estudo sobre erros conceituais em livros didáticos. Investigações em Ensino de Ciências 10(3): 281-298.

Santos-Fita, D. 2008. Cobra é Inseto que Ofende: classificação etnobiológica, questões sanitárias e conservação na região Serra da Jibóia, estado da Bahia, Brasil. Dissertação de Mestrado. Universidade Estadual de Santa Cruz.

Schlaepfer M.A.; Hoover, C. \& Dodd, C.K. 2005. Challenges in evaluating the impact of the trade in amphibians and reptiles on wild populations. Bioscience 55: 255-264.

Seburn, D. \& Seburn, C. 2000. Conservation Priorities for the Amphibians and Reptiles of Canada. WWF, Toronto.

Seigel, R.A.; Collins, J.T. \& Novak, S.S. 1987. Snakes: ecology and evolutionary biology. McGraw-Hill, New York.

Shine, R. \& Koenig, J. 2001. Snakes in the garden: an analysis of reptiles "rescued" by community-based wildlife careers. Biological Conservation 102(3): 271-283.

Silva-Júnior, N.J. \& Bucaretchi, F. 2003. Mecanismo de ação do veneno elapídico e aspectos clínicos dos acidentes. In: J.L.C. Cardoso, F.O.S. França, F.H. Wen, C.M.S. Malaque \&
V. Haddad-Junior (eds), Animais Peçonhentos no Brasil: biologia, clínica e terapêutica dos acidentes. Sarvier, São Paulo.

Smith, M. \& Davidson, J. 2007. 'It makes my skin crawl...': the embodiment of disgust in phobias of 'nature'. Body \& Society 12(1): 43-67.

Tolson, P.J. \& Henderson, R.W. 2006. An overview of snake conservation in the West Indies. Applied Herpetology 3(4): 345-356.

Vanzolini, P.E. 1956-1958. Notas sobre a zoologia dos índios Canela. Revista do Museu Paulista 10: 155-171.

Vanzolini, P.E.; Ramos-Costa, A.M.M. \& Vitt, L.J. 1980. Répteis das Caatingas. Academia Brasileira de Ciências, Rio de Janeiro.

Vizotto, L.D. 2003. Serpentes: lendas, mitos, superstições e crendices. Plêiade, São Paulo.

Wilson, E.O. 1984. Biophilia. Havard University Press, Cambridge.

Zamudio, K.R. \& Greene, H.W. 2008. Phylogeography of the bushmaster (Lachesis muta: Viperidae): implications for neotropical biogeography, systematics, and conservation. Biological Journal of Linnean Society 62(3): 421-442.

Zug, G.R.; Vitt, L.J. \& Caldwell, L.P. 2001. Herpetology: an introductory biology of amphibians and reptiles. 2 ed. Academic Press, San Diego. 